\title{
A Simple and Fast Separation Method of Fe Employing Extraction Resin for Isotope Ratio Determination by Multicollector ICP-MS
}

\author{
Akio Makishima \\ The Pheasant Memorial Laboratory for Geochemistry and Cosmochemistry (PML), Institute for Study of the Earth's Interior, \\ Okayama University, Misasa, Tottori, Japan \\ Email: max@misasa.okayama-u.ac.jp
}

Received October 17, 2013; revised November 13, 2013; accepted December 16, 2013

Copyright (C) 2013 Akio Makishima. This is an open access article distributed under the Creative Commons Attribution License, which permits unrestricted use, distribution, and reproduction in any medium, provided the original work is properly cited.

\begin{abstract}
A new, simple and fast separation method for Fe using an extraction chromatographic resin, Aliquat 336 (commercially available as TEVA resin) has been developed. A one milliliter column containing $0.33 \mathrm{~mL}$ TEVA resin on $0.67 \mathrm{~mL}$ CG-71C was used. Iron was adsorbed with $6 \mathrm{~mol} \cdot \mathrm{L}^{-1} \mathrm{HCl}+\mathrm{H}_{2} \mathrm{O}_{2}$ on TEVA resin, and recovered with $2 \mathrm{~mol} \cdot \mathrm{L}^{-1} \mathrm{HNO}_{3}$. The recovery yield and total blank were $93.5 \pm 6.5 \%$ and $6 \mathrm{ng}$, respectively. The separation method is simple, and takes $<2$ hours. For evaluation of the Fe separation, $\mathrm{Fe}$ isotope ratios were measured by a double-spike method employing multicollector inductively coupled plasma source mass spectrometry (MC-ICP-MS) with repeatability of $0.06 \%$ (SD) for the standard solution and $\sim 0.05 \%$ for the silicate samples. Therefore, the column chemistry developed in this study is a viable option for Fe isotope ratio measurement by MC-ICP-MS.
\end{abstract}

Keywords: Fe Separation; Fe Isotope Ratio; Multicollector Inductively Coupled Plasma Source Mass Spectrometry

\section{Introduction}

Trioctylmethylammonium chloride (Aliquat 336) works as an anion exchanger, and is used in extraction chromatography (commercially sold as TEVA resin) [1]. Yang and Pin [2] and Grahek and Macefat [3] have tried to use the TEVA resin for Fe separation. The eluent volumes of $60 \mathrm{~mL}$ for $1 \mathrm{~mL}$ of the TEVA resin and $120 \mathrm{~mL}$ for $3 \mathrm{~g}$ (equates $\sim 2.7 \mathrm{~mL}$ ) TEVA resin were used, respectively. However, these volumes are too mamy to handle; large space is required and evaporation takes a long time. Recently, Makishima and Nakamura [4] successfully purified $\mathrm{Zn}$ using a one milliliter column composed of 0.33 $\mathrm{mL}$ TEVA resin on $0.67 \mathrm{~mL}$ CG-71C resin. They used the advantage of acid resistance of the TEVA resin [5], namely, $\mathrm{HNO}_{3}$ was used in the final step to recover $\mathrm{Zn}$ that was strongly adsorbed on the resin. Based on this novel finding, it was noticed that the anionic character of the TEVA resin could be applied to separation of Fe. This study applies the TEVA resin for purification of Fe for isotope ratio measurements using multicollector (MC)-ICP-MS for the first time.

An advantage of the new TEVA resin column chemis- try is that the whole column chemistry (from sample loading to $\mathrm{Fe}$ collection) finishes $<2$ hours. Anion exchange resins, AG $1 \mathrm{X} 8$ or AG MP-1 employing Fe(III) chloro complex are commonly used [6,7]. In a one milliliter of AG 1X8 column case, for example, the total volume of $55 \mathrm{~mL}$ [7], was used from washing the column to collection of Fe. Using an AG MP-1 column, total elution volume for Fe was reduced to $22 \mathrm{~mL}$ [6].

For evaluation of column chemistry and mass spectrometry developed in this study, three USGS (the US Geological Survey) standard silicate reference materials, seven GSJ (the Geological Survey of Japan) standard silicate reference materials and three carbonaceous chondrites of Orgueil, Murchison and Allende were used as test samples. Then Fe isotope ratios were measured using a double spike method [8-11] at high mass resolution by MC-ICP-MS to show the validity of the method.

\section{Experimental}

\subsection{Reagents}

All experiments were performed in clean rooms and clean benches with HEPA (High Efficiency Particulate 
Air) filter in the Pheasant Memorial Laboratory (PML) [12]. Water and HF were purified as described elsewhere [12]. Hydrochloric acid was distilled by a Teflon-twobottle distiller [12]. TAMAPURE-AA-100 grade perchloric acid (Tama Chemicals Co., Ltd., Japan), electric industry (EL) grade $\mathrm{HNO}_{3}$ and ultrapure hydrogen peroxide (Kanto Chemical Co. Inc., Japan) were used without purification. Six mol $\cdot \mathrm{L}^{-1} \mathrm{HCl}$ with $0.05 \%(\mathrm{v} / \mathrm{v}) \mathrm{H}_{2} \mathrm{O}_{2}$ was prepared just before the column chemistry. For the column calibration, two multi-element standard solutions (Specpure, Nos. 42885 and 44270, Alfa Aesar, USA) were used.

CAUTION: $\mathrm{HF}, \mathrm{HCl}, \mathrm{HNO}_{3}, \mathrm{HClO}_{4}$ and $\mathrm{H}_{2} \mathrm{O}_{2}$ are highly corrosive and toxic. Inhalation and contact with skin and eyes should be avoided. They should be handled with protective glasses and gloves.

Iron standard metal, IRMM-014 was dissolved, and finally diluted into $1 \mu \mathrm{g} \cdot \mathrm{mL}^{-1}$ with $0.5 \mathrm{~mol} \cdot \mathrm{L}^{-1} \mathrm{HNO}_{3}$ and used as the isotopic standard for MC-ICP-MS. TEVA extraction resin (100 - $150 \mu \mathrm{m}$, Eichrom Technologies, Inc., USA) and Amberchrom CG-71C (Rohm and Haas, Co., USA) were soaked and stored in water. TEVA resin and CG-71C were not reused.

\subsection{Iron Double Spike}

A ${ }^{57} \mathrm{Fe}-{ }^{58} \mathrm{Fe}$ double spike $[10,11]$ was chosen. Iron isotopes of ${ }^{57} \mathrm{Fe}$ and ${ }^{58} \mathrm{Fe}$, with enrichments of 86.06 and $73.51 \%$, respectively, were purchased from Oak Ridge National Laboratory (USA). Each spike was dissolved and diluted with $\mathrm{HNO}_{3}$, then mixed and used as a Fe double spike. Ideal isotopic abundances of the double spike were 47.65 and $52.35 \%$ for ${ }^{57} \mathrm{Fe}$ and ${ }^{58} \mathrm{Fe}$, respectively [10], and the best sample: spike mole ratio is 55:45 [10]. Therefore, $1 \mu \mathrm{g}$ sample Fe was mixed with $0.8 \mu \mathrm{g}$ double-spike. To keep this ratio, the Fe concentration in the sample solution was determined before the spike addition by high-resolution ICP-MS [13].

\subsection{Silicate Samples}

Three USGS silicate reference materials, BHVO-1 (basalt), AGV-1 (andesite) and PCC-1 (peridotite) and seven GSJ silicate reference materials, JB-1, JB-2, JB-3 (basalts), JA-1, JA-2, JA-3 (andesites) and JP-1 (peridotite) were used as test samples. Powder of bulk carbonaceous chondrites, Orgueil (CI1), Murchison (CM2) and Allende (CV3) were also employed.

\subsection{TEVA Resin Column and Silicate Sample Solution}

The TEVA resin column was prepared by packing 0.33 $\mathrm{mL}$ of TEVA resin on $0.67 \mathrm{~mL}$ of CG-71C in a $1 \mathrm{~mL}$ polypropylene column $(5 \mathrm{~cm} \times 5 \mathrm{~mm}$ in diameter, Muromachi Chemicals Inc., Japan) [4]. The CG-71C resin was used for absorbing organic materials and controlling the elution rate.

Silicate powder samples were digested by a usual sample digestion method in our laboratory [13]. In short, samples were digested with $\mathrm{HF}-\mathrm{HClO}_{4}$, dried to decompose fluorides with $\mathrm{HClO}_{4}$ again [14], evaporated with $\mathrm{HCl}$, and finally dissolved with $0.5 \mathrm{~mol} \cdot \mathrm{L}^{-1} \mathrm{HNO}_{3}$. The final dilution was typically $\sim 250$ times (20 mg silicate samples into $5 \mathrm{~mL}$ ).

\subsection{Iron Separation by the TEVA Resin Column}

A Fe separation procedure using the TEVA resin column is summarized in Table 1. All $\mathrm{H}_{2} \mathrm{O}_{2}$ concentration in Table 1 is $0.05 \%(\mathrm{v} / \mathrm{v}) \mathrm{H}_{2} \mathrm{O}_{2}$. The resin bed was washed twice with $2 \mathrm{~mol} \cdot \mathrm{L}^{-1} \mathrm{HNO}_{3}$, subsequently washed once with $6 \mathrm{~mol} \cdot \mathrm{L}^{-1} \mathrm{HCl}$, and conditioned. The sample solution containing $1 \mu \mathrm{g}$ of $\mathrm{Fe}$ was added with the solution containing $0.8 \mu \mathrm{g} \mathrm{Fe}$ double spike and $0.6 \mathrm{~mL}$ of 6 $\mathrm{mol} \cdot \mathrm{L}^{-1} \mathrm{HCl}$, and dried. Then the sample was dissolved with $0.1 \mathrm{~mL}$ of $6 \mathrm{~mol} \cdot \mathrm{L}^{-1} \mathrm{HCl}$ with $\mathrm{H}_{2} \mathrm{O}_{2}$, loaded on the resin bed and left for 5 min (see Results and Discussion). The major elements were washed away by addition of $3.2 \mathrm{~mL}$ of $6 \mathrm{~mol} \cdot \mathrm{L}^{-1} \mathrm{HCl}$ with $\mathrm{H}_{2} \mathrm{O}_{2}$. Then $\mathrm{Fe}$ was collected with $6.4 \mathrm{~mL}$ of $2 \mathrm{~mol} \cdot \mathrm{L}^{-1} \mathrm{HNO}_{3}$. The $\mathrm{Fe}$ fraction was dried at $80^{\circ} \mathrm{C}$ for 10 hours with one drop of $\mathrm{HClO}_{4}$ to decompose organic materials and small resin particles. To evaporate $\mathrm{HClO}_{4}$ completely, the sample was finally heated at $195^{\circ} \mathrm{C}$ for 6 hours. Then the purified $\mathrm{Fe}$ was dissolved with $1 \mathrm{~mL}$ of $0.5 \mathrm{~mol} \cdot \mathrm{L}^{-1} \mathrm{HNO}_{3}$, which is ready for MC-ICP-MS measurement.

Although the flow rate of the TEVA column is 0.3 $\mathrm{mL} \cdot \mathrm{min}^{-1}$, which is rather high, breakthrough of $\mathrm{Fe}$ does not occur. As the total elution volume including washing of the column is $32.1 \mathrm{~mL}$, the column chemistry can be finished within two hours including washing and conditioning the resin bed. This is one of the largest advantages of the TEVA resin column chemistry developed in this study. In a case of $1 \mathrm{~mL}$ of AG $1 \mathrm{X} 8$, the flow rate of a column is $\sim 0.2 \mathrm{~mL} \cdot \mathrm{min}^{-1}$, and the total elution volume is $\sim 55 \mathrm{~mL}$ [7]. Thus it takes more than 5 hours to collect Fe. In addition in other studies, one pass of anion ex-

Table 1. Chemical procedure for Fe purification using TEVA resin column.

\begin{tabular}{ccc}
\hline & $2 \mathrm{~mol} \cdot \mathrm{L}^{-1} \mathrm{HNO}_{3}$ & $6.4 \mathrm{~mL}$ \\
Washing & water & $1.6 \mathrm{~mL}$ \\
& $2 \mathrm{~mol} \cdot \mathrm{L}^{-1} \mathrm{HNO}_{3}$ & $6.4 \mathrm{~mL}$ \\
water & $1.6 \mathrm{~mL}$ \\
Conditioning & $6 \mathrm{~mol} \cdot \mathrm{L}^{-1} \mathrm{HCl}$ & $3.2 \mathrm{~mL}$ \\
Loading the sample (leave 5 min) & $6 \mathrm{~mol} \cdot \mathrm{L}^{-1} \mathrm{HCl}+\mathrm{H}_{2} \mathrm{O}_{2}$ & $0.1 \mathrm{~mL}$ \\
Removing major elements & $6 \mathrm{~mol} \cdot \mathrm{L}^{-1} \mathrm{HCl}+\mathrm{H}_{2} \mathrm{O}_{2}$ & $3.2 \mathrm{~mL}$ \\
Collecting Fe & $2 \mathrm{~mol} \cdot \mathrm{L}^{-1} \mathrm{HNO}_{3}$ & $6.4 \mathrm{~mL}$ \\
\hline
\end{tabular}


change column is not enough, and the column chemistry is repeated twice or three times to purify $\mathrm{Fe}$ in some cases [7].

The combination with the double spike technique of this column chemistry gives another advantage that the Fe isotope determination is more tolerable to loss of iron, which could occur in the column chemistry.

\subsection{Measurement of Fe Isotope Ratios}

Isotope ratios of Fe were measured by an MC-ICP-MS, NEPTUNE housed in PML. Details of the MC-ICP-MS operating conditions are shown in Table 2 . The spiked 1 $\mu \mathrm{g} \cdot \mathrm{mL}^{-1}$ of Fe solution generally gave $\sim 2 \times 10^{-10}$ A signal for ${ }^{56} \mathrm{Fe}^{+},{ }^{57} \mathrm{Fe}^{+}$and ${ }^{58} \mathrm{Fe}^{+}$. One run consists of 70 scans, but the first 40 scans were not used and the following 30 scans were used, because the signal increased slowly and stabilized after around 40 scans. Thirty sets of isotope ratios of ${ }^{56} \mathrm{Fe} /{ }^{54} \mathrm{Fe},{ }^{57} \mathrm{Fe} /{ }^{54} \mathrm{Fe}$ and ${ }^{58} \mathrm{Fe} /{ }^{54} \mathrm{Fe}$

Table 2. MC-ICP-MS operating conditions.

\begin{tabular}{|c|c|c|c|c|}
\hline \multicolumn{5}{|c|}{ 1) Sample introduction and ICP conditions } \\
\hline \multirow{4}{*}{\multicolumn{2}{|c|}{ Nebulizer }} & \multicolumn{3}{|c|}{ Micro-flow PFA nebulizer, } \\
\hline & & \multicolumn{3}{|c|}{ PFA-50 (ESI, USA) } \\
\hline & & \multicolumn{3}{|c|}{ self-aspiration } \\
\hline & & \multicolumn{3}{|c|}{ flow rate: $\sim 50 \mu \mathrm{L} \cdot \min ^{-1}$} \\
\hline \multicolumn{2}{|c|}{ Plasma power } & \multicolumn{3}{|c|}{$1.2 \mathrm{~kW}(27.12 \mathrm{MHz})$} \\
\hline \multirow{2}{*}{\multicolumn{2}{|c|}{ Torch }} & \multicolumn{3}{|c|}{ Quartz glass torch } \\
\hline & & \multicolumn{3}{|c|}{ with a sapphire injector } \\
\hline Plas & $\mathrm{W}$ rate & \multicolumn{3}{|c|}{$15 \mathrm{~L} \cdot \min ^{-1}$} \\
\hline Auxil & ow rate & \multicolumn{3}{|c|}{$0.80 \mathrm{~L} \cdot \min ^{-1}$} \\
\hline Nebul & ow rate & \multicolumn{3}{|c|}{$0.90 \mathrm{~L} \cdot \min ^{-1}$} \\
\hline \multicolumn{5}{|c|}{ 2) Desolvator conditions } \\
\hline & & \multicolumn{3}{|c|}{ ARIDUS II } \\
\hline Spray & perature & \multicolumn{3}{|c|}{$110^{\circ} \mathrm{C}$} \\
\hline Desc & rature & \multicolumn{3}{|c|}{$160^{\circ} \mathrm{C}$} \\
\hline & & \multicolumn{3}{|c|}{$8-9 \mathrm{~L} \cdot \mathrm{min}^{-1}$} \\
\hline \multicolumn{5}{|c|}{ 3) Interface } \\
\hline & & \multicolumn{3}{|c|}{ Made of $\mathrm{Ni}$} \\
\hline & & \multicolumn{3}{|c|}{ Made of Ni (X-skimmer) } \\
\hline \multicolumn{5}{|c|}{ 4) Data acquisition conditions } \\
\hline & & \multicolumn{3}{|c|}{$\mathrm{M} / \Delta \mathrm{M}=\sim 7000$} \\
\hline & & \multicolumn{3}{|c|}{$480 \mathrm{sec}$ after measurement } \\
\hline & & \multicolumn{3}{|c|}{$90 \mathrm{sec}$} \\
\hline \multirow{2}{*}{\multicolumn{2}{|c|}{ Background data integration }} & \multicolumn{3}{|c|}{$4 \mathrm{sec}$ for $1 \mathrm{scan}, 20$ scans in one run } \\
\hline & & \multicolumn{3}{|c|}{ On-top zeroes } \\
\hline Sam & ration & \multicolumn{3}{|c|}{$4 \mathrm{sec}$ for 1 scan, 30 scans in one run } \\
\hline \multicolumn{5}{|c|}{ 5) Cup configuration } \\
\hline L4 & L1 & $\mathrm{C}$ & & $\mathrm{H} 4$ \\
\hline${ }^{52} \mathrm{Cr}^{*}$ & ${ }^{54} \mathrm{Fe}$ & ${ }^{56} \mathrm{Fe}$ & & ${ }^{60} \mathrm{Ni}$ \\
\hline
\end{tabular}

*An amplifier with a $1 \mathrm{~T} \Omega$ resistor. were obtained for each sample, and the averages of each ratio were calculated. Then the double spike calculation (see the next section) was performed. One $\mathrm{T}$ ohm resistor amplifier [15] was used (see Table 2), and ${ }^{52} \mathrm{Cr}$ and ${ }^{53} \mathrm{Cr}$ were sometimes observed. Isobaric interference of ${ }^{54} \mathrm{Cr}$ was corrected using ${ }^{54} \mathrm{Cr} /{ }^{52} \mathrm{Cr}=0.11339$, a power law, and a normalizing value of ${ }^{53} \mathrm{Cr} /{ }^{52} \mathrm{Cr}=0.028226$ [16]. Nickel interference was corrected using ${ }^{58} \mathrm{Ni} /{ }^{60} \mathrm{Ni}=2.62$.

The $\mathrm{Fe}$ isotope fractionation is expressed as a per mil difference from that of the Fe standard, IRMM-014 [17] by the following equation:

$$
\begin{aligned}
\delta^{56} \mathrm{Fe} & =\left[\left({ }^{56} \mathrm{Fe} /{ }^{54} \mathrm{Fe}\right)_{\text {sample }} /\left({ }^{56} \mathrm{Fe} /{ }^{54} \mathrm{Fe}\right)_{\text {IRMM }-014}-1\right] \\
& \times 1000
\end{aligned}
$$

\subsection{Double Spike Calculation}

A theory of a double spike is briefly explained in this section. Each Fe ratio is written using an exponential law as follows:

$$
\begin{aligned}
& \mathrm{R}_{\text {norm }-i / 54} / \mathrm{R}_{\text {smp }-i / 54}=\left(m_{i} / m_{54}\right) \wedge\left(\phi m_{54}\right) \\
& (i=56,57 \text { and 58) }
\end{aligned}
$$

where $m_{i}$ is a mass of ${ }^{\mathrm{i}} \mathrm{Fe} ; \mathrm{R}_{\text {norm-i/54 }}$ and $\mathrm{R}_{\text {smp-i/54 }}$ indicate normalizing and sample isotope ratios of ${ }^{\mathrm{i}} \mathrm{Fe} /{ }^{54} \mathrm{Fe}$. In this study, $\mathrm{R}_{\text {norm-i/54 }}(i=56,57$ and 58) are 15.698, 0.36233 and 0.048080 , respectively, which are those of the standard IRMM-014 [17]. It should be noted that $\mathrm{R}_{\text {norm-i/54 }}$ and $m_{i}$ are constants. $\phi$ is a mass fractionation factor, which is a product of mass fractionation of the sample and mass discrimination during analysis.

When there is no fractionation in the sample, $\phi$ is equal to 0 . Thus the sample isotope ratios become equal to those of IRMM-014. The purpose is to determine $\mathrm{R}_{\text {smp-i/54. }}$ For this purpose, a double spike method has been developed [8-11].

The spike isotope ratios of $\mathrm{R}_{\text {spike-i/54 }}(i=56,57$ and 58) also follow the similar equations:

$$
\begin{aligned}
& \mathrm{R}_{\text {spike }-i / 54} / \mathrm{R}_{\text {spike' }-i / 54}=\left(m_{i} / m_{54}\right) \wedge\left(\phi^{\prime} m_{54}\right) \\
& (i=56,57 \text { and 58) }
\end{aligned}
$$

When the spike isotope ratios are measured, only $\mathrm{R}_{\text {spike'-i/54 }}$ are obtained, and $\mathrm{R}_{\text {spike-i/54, which are isotope }}$ ratios without mass fractionation $\left(\phi^{\prime}=0\right)$, cannot be determined. The method for determination of $\mathrm{R}_{\text {spike-i/54, }}$ which is called as "spike calibration", is described later.

For the spike-sample mixture, the following equations hold:

$$
\begin{aligned}
& \mathrm{R}_{\text {mix }-i / 54}=\left[b\left(\mathrm{R}_{\text {smp }-i / 54}\right)+\left(\mathrm{R}_{\text {spike }-i / 54}\right)\right] /(1+b) \\
& (i=56,57 \text { and } 58) \\
& \quad R_{\text {mix }-i / 54} / R_{\text {mix }^{\prime}-i / 54}=\left(m_{i} / m_{54}\right) \wedge\left(\phi^{\prime \prime} m_{54}\right) \\
& \quad(i=56,57 \text { and } 58)
\end{aligned}
$$


where $b$ is mixing mole ratio of the sample to the spike. The three isotope ratios of the spike-sample mixtures $\left(\mathrm{R}_{\text {mix'-i/54; }} ;=56,57\right.$ and 58) are measured. As there are nine variables $\left(\mathrm{R}_{\text {smp- }-i / 54}, \mathrm{R}_{\text {mix- }-/ 54}, b, \phi\right.$ and $\phi^{\prime \prime} ; i=56,57$ and 58) and nine equations (Equations (2-4); (8-13)), there should be solutions for these variables. In this study, a calculation [9] to solve these equations was followed, in which exponential approximation is used. Finally, a fractionation degree of the unknown sample, $\delta^{56} \mathrm{Fe}$ (Equation (1)) can be determined.

The spike calibration method is as follows. First, the pure spike is measured. In this study, the averages of the pure spike isotope ratios, $\mathrm{R}_{\text {spike'-i/54 }}(i=56,57$ and 58) are obtained to be 25.927, 52.110 and 58.973, respectively. Then, mixtures of the spike and the standard, IRMM-014 were prepared and measured. Then, the spike isotope ratio of $\mathrm{R}_{\text {spike-56/54 }}$ and $\phi^{\prime}$ are determined to minimize the difference between the ${ }^{56} \mathrm{Fe} /{ }^{54} \mathrm{Fe}$ ratio of IRMM-014 and the average of the ${ }^{56} \mathrm{Fe} /{ }^{54} \mathrm{Fe}$ ratio obtained from the double spikes calculation using Microsoft-Excel "Solver".

In the actual sample measurement, the spike-sample mixture is bracketed by the spike-standard mixture. Then from all the spike-standard isotope ratios, the average of $\mathrm{R}_{\text {spike-56/54 }}$ and the optimum $\phi^{\prime}$ in one session are obtained. Then the ${ }^{56} \mathrm{Fe} /{ }^{54} \mathrm{Fe}$ ratios of the sample and the standard before and after the sample measurement are calculated. Finally, $\delta^{56} \mathrm{Fe}$ of each sample is determined. In this calculation, the typical error of ${ }^{56} \mathrm{Fe} /{ }^{54} \mathrm{Fe}$ of the standard solution was $0.06 \%$ o (SD).

\section{Results and Discussion}

\subsection{Kinetic Effects in Adsorption of Fe}

For the TEVA resin, kinetic effects in adsorption of $\mathrm{Fe}$ are not negligible [5]. Therefore, the kinetic effects in the adsorption of Fe were examined. The Fe standard solutions were loaded on the TEVA column with adsorption time of 5, 10, 25 and 55 min. Then Fe was collected, and the yields were measured.

Analytical results are shown in Figure 1. The recovery of $\mathrm{Fe}$ was $\sim 100 \%$ after $5 \mathrm{~min}$. However, the recovery yields of $>5$ min seem a bit lower than $100 \%$. Therefore, the optimal adsorption reaction time is determined as 5 min. When the adsorption reaction time becomes longer than $5 \mathrm{~min}$, some Fe ion cannot be desorbed from the resin by $6.4 \mathrm{~mL}$ of $2 \mathrm{~mol} \cdot \mathrm{L}^{-1} \mathrm{HNO}_{3}$.

\subsection{Elution Curves of Fe in the TEVA Column}

An elution curve of Fe of the TEVA column is shown in Figure 2. In the figure, only $\mathrm{Mg}$ and Fe are plotted, however, other major elements in silicate samples such as $\mathrm{Na}$, $\mathrm{Al}, \mathrm{P}, \mathrm{Ca}, \mathrm{Cr}, \mathrm{Mn}$ and $\mathrm{Ni}$ behave similarly to $\mathrm{Mg}$. As shown in Figure 2, almost $100 \%$ of major elements in

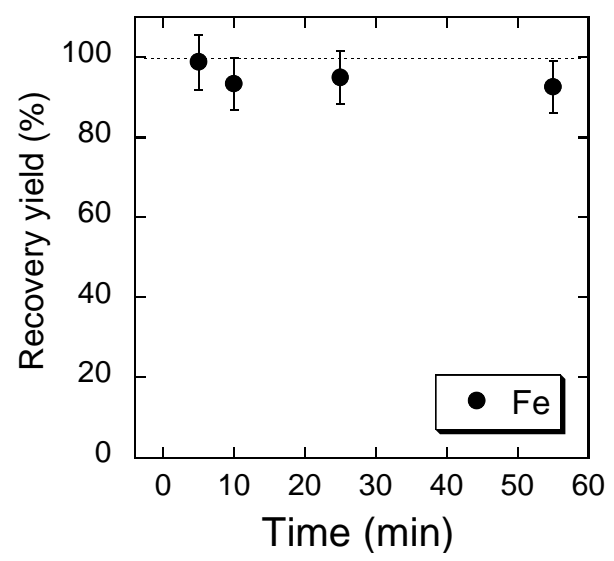

Figure 1. The sample adsorption time (min) after sample loading vs. the recovery yield (\%). Error bars are the quantitative analytical error of $\sim 7 \%$. The dotted horizontal line shows $100 \%$ yield.

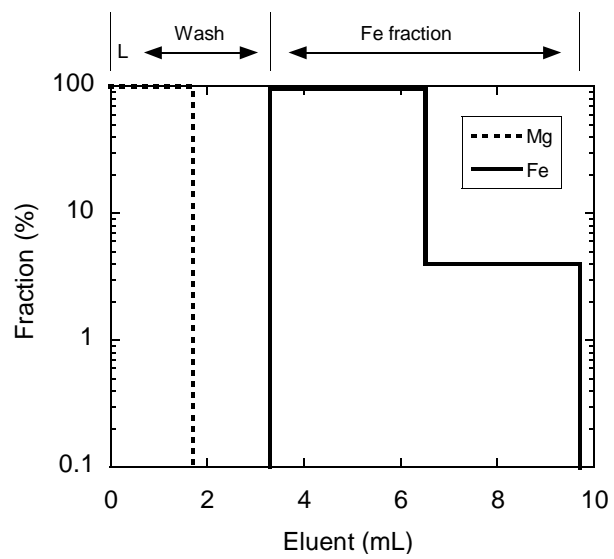

Figure 2. Elution curves of Fe and Mg for the TEVA column. Mg represents behaviors of $\mathrm{Na}, \mathrm{Al}, \mathrm{P}, \mathrm{K}, \mathrm{Ca}, \mathrm{Cr}, \mathrm{Mn}$, $\mathrm{Fe}, \mathrm{Co}$ and $\mathrm{Ni}$. The horizontal axis shows total eluent volume $(\mathrm{mL})$. The vertical axis indicates fraction (\%) recovered from each eluent fraction (\%) compared to the added amounts on the column. The vertical axis is in the logarithmic scale. The horizontal arrows at the top show the eluents for wash and Fe fraction, respectively. " $L$ " indicates the sample loading solution.

silicate samples added in the column are washed away in the first $1.6 \mathrm{~mL}$ of $6 \mathrm{~mol} \cdot \mathrm{L}^{-1} \mathrm{HCl}$ with $\mathrm{H}_{2} \mathrm{O}_{2}$. The total yield of Fe using actual silicate samples was $93.5 \pm$ $6.5 \%$ (SD). This result means that there could be a small loss of Fe in this study. Such loss of Fe could cause isotopic fractionation [18]. However, such fractionation can be corrected by the double spike method employed in this study.

Zinc, $\mathrm{Ga}, \mathrm{Nb}, \mathrm{Mo}, \mathrm{Ta}, \mathrm{W}$ and $\mathrm{U}$ were contained in the Fe fraction with yields of $60 \%-90 \%$. However, in usual silicate samples, amounts of these elements compared to $1 \mu \mathrm{g} \mathrm{Fe}$ are $<$ ng levels, therefore, effects of these impurities are inconsequential. Furthermore, total yields of $\mathrm{Nb}$, $\mathrm{Ta}$ and $\mathrm{W}$ from the sample solution should be lower than 
those of the starting solution, because co-precipitation with $\mathrm{Ti}$ oxides of $\mathrm{Nb}$, Ta and $\mathrm{W}$ should occur during sample evaporation using $\mathrm{HClO}_{4}$ [19].

The total blanks including sample digestion were $6 \mathrm{ng}$ $(\mathrm{n}=6)$. As $\delta^{56} \mathrm{Fe}$ range of all natural samples is $< \pm 3 \%$ [7], $\delta^{56} \mathrm{Fe}$ of blank can be assumed to be $< \pm 3 \%$. Since Fe in the sample is $1 \mu \mathrm{g}$, the maximum shift of $\delta^{56} \mathrm{Fe}$ by the blank should be $< \pm 0.02 \%$. As the repeatability of the standard solution was found to be $0.06 \%$, the blank effects are less than one thirds of the repeatability of the standard solution. Thus the blank effect can be neglected.

\subsection{Evaluation of Accuracy in Fe Isotope Ratio Measurement}

It is difficult to evaluate the accuracy in stable isotope mass spectrometry for less popular elements such as Fe, because the standard materials with accurate isotope ratios are limited. In this study, to examine the accuracy with variable isotope ratios and matrix elements, the synthesized samples were made by mixing of two samples with different isotope ratios and matrix element compositions. Then the isotope ratios of the mixture were compared with the calculated isotope ratios. Such mixing tests were done in studies of $\mathrm{Zn}$ and $\mathrm{Tl}$ isotopes to evaluate the accuracy of the method $[4,20]$.

For one sample, one of the JB-2 solutions of $\delta^{56} \mathrm{Fe}=$ $-0.27 \pm 0.03$ (see the next section) was used. For the other sample, one of ferruginous bodies-digested solutions [21] of $\delta^{56} \mathrm{Fe}=-3.16 \pm 0.09(\mathrm{n}=4)$ (private communication, Makishima and Nakamura, Okayama University, Dec. 2012) was used. This solution was prepared by ashing the ferruginous bodies separated from human lung and dissolving with nitric acid. This solution has a very low $\delta^{56} \mathrm{Fe}$ value, and is mostly composed of $\mathrm{Fe}$ [21]. The JB-2 and ferruginous bodies-digested solutions were taken and mixed to contain $1 \mu \mathrm{g}$ of Fe. Three types of the mixtures with different matrix compositions were made. For each type of the mixtures, four or five samples were made. Each sample was added with $0.4 \mathrm{~mL} 6 \mathrm{~mol} \cdot \mathrm{L}^{-1}$ $\mathrm{HCl}$ and the $\mathrm{Fe}$ double spike, dried and passed through the TEVA column. Then Fe was collected and its isotope ratio was determined by MC-ICP-MS.

Analytical results of the $\delta^{56} \mathrm{Fe}$ value of each mixture are shown in Table 3. The calculated values are also shown in Table 3. The error in calculation for each mixture was based on concentration error of $\sim 5 \%$ of two starting solutions, and no other errors are taken into account. From Table 3, the observed values are consistent with the calculated values within 2 SD ranges, although the three samples had different major element compositions. Therefore, it is suggested that the double spike method for Fe isotope measurements using MC-ICP-MS in this study gives accurate isotope ratios of $\mathrm{Fe}$.

\subsection{Fe Isotope Ratio Measurements in Silicate Reference Materials}

The TEVA column chemistry developed in this study was applied to analysis of the silicate reference materials, and analytical results are presented in Table 4, together with the reported values $[11,22-26]$. To make the comparison between $\delta^{56} \mathrm{Fe}$ of this study and those of references easier, they are plotted in Figure 3. The $\delta^{56} \mathrm{Fe}$ value of BHVO-1 in this study of $0.18 \%$ is a little higher than those of references [22-24,26]. The $\delta^{56} \mathrm{Fe}$ values of AGV- 1 and PCC- 1 of this study are -0.10 and $0.00 \%$, respectively, which are consistent with those of previous studies $[21,25,26]$ when errors are taken into account.

Repeatability for silicate reference materials (Table 4) is $0.03 \%$ - $0.06 \%$, and the average is $0.05 \%$. This $0.05 \%$ should be considered as repeatability of actual silicate analysis by MC-ICP-MS in this study. As discussed previously, the blank effects are $\pm 0.02 \%$, however, this can be negligible to $0.05 \%$, which is considered to be repeatability of this method. This value is similar to that of the pure standard solution $(0.06 \%)$ ).

The repeatability in the Fe standard solution is compared with those of references here. The SD values of replicate analyses of the standard solution are $0.013,0.10$, $0.010,0.050$ and $0.041 \%$ in Chicago [22], Woods Hole [23], Hannover [24], Madison [25], and Frankfurt [26] groups, respectively. Therefore the repeatability of the MC-ICP-MS methods of these leading groups which use the bracketing method is similar or a bit better than that of this study. However, all groups use AG 1X8, so they need repetitive column chemistry in many cases, because $\mathrm{Fe}$ cannot be purified enough by the single column chemistry to be used in the mass spectrometry. However, other groups [11] which use AG MP-1 can purify Fe by a single column chemistry.

Recently, Millet et al. [11] achieved "ultra-precise" Fe measurements, using the same pair of the double spike, ${ }^{57} \mathrm{Fe}-{ }^{58} \mathrm{Fe}$. They constantly achieved the repeatability of

Table 3. Analytical results of mixing experiments.

\begin{tabular}{|c|c|c|c|c|c|}
\hline & Calculated & & Observed & & \\
\hline & $\delta^{56} \mathrm{Fe}$ & SD (\%o) & $\delta^{56} \mathrm{Fe}$ & SD (\%o) & $\mathrm{n}$ \\
\hline Mixture\#1 & -1.12 & 0.08 & -1.36 & 0.04 & 4 \\
\hline Mixture\#3 & -2.50 & 0.17 & -2.64 & 0.05 & 5 \\
\hline
\end{tabular}


Table 4. $\delta^{56} \mathrm{Fe}$ values of USGS and GSJ silicate reference materials and carbonaceous chondrites.

\begin{tabular}{ccccc}
\hline Sample & Average & SD & $\mathrm{n}$ & References \\
\hline & $\delta^{56} \mathrm{Fe}$ & $(\%)$ & & (Error is SD) \\
BHVO-1 & 0.18 & 0.03 & 3 & $0.105 \pm 0.008[22], 0.110 \pm 0.060[23], 0.109 \pm 0.024[24], 0.117 \pm 0.015[26]$ \\
AGV-1 & -0.10 & 0.06 & 3 & $0.04 \pm 0.01[24]$ \\
PCC-1 & 0.00 & 0.02 & 3 & $0.025 \pm 0.012[22],-0.06 \pm 0.06[25], 0.043 \pm 0.013[26]$ \\
JB-1 & -0.14 & 0.05 & 4 & $0.073 \pm 0.014[11]$ \\
JB-2 & -0.27 & 0.03 & 4 & $0.060 \pm 0.010[11]$ \\
JB-3 & -0.35 & 0.08 & 3 & \\
JA-1 & -0.13 & 0.06 & 4 & \\
JA-2 & -0.02 & 0.03 & 4 & $-0.015 \pm 0.074[26], 0.38[27], 0.04 \pm 0.06[28]$ \\
JA-3 & 0.09 & 0.06 & 4 & $-0.12 \pm 0.06[28]$ \\
JP-1 & -0.54 & 0.06 & 4 & $-0.007 \pm 0.012[22],-0.04[27],-0.06 \pm 0.01[28]$ \\
Orgueil & -0.05 & 0.06 & 3 & \\
Murchison & -0.10 & 0.12 & 3 & \\
Allende & -0.03 & 0.03 & 3 & \\
\hline
\end{tabular}

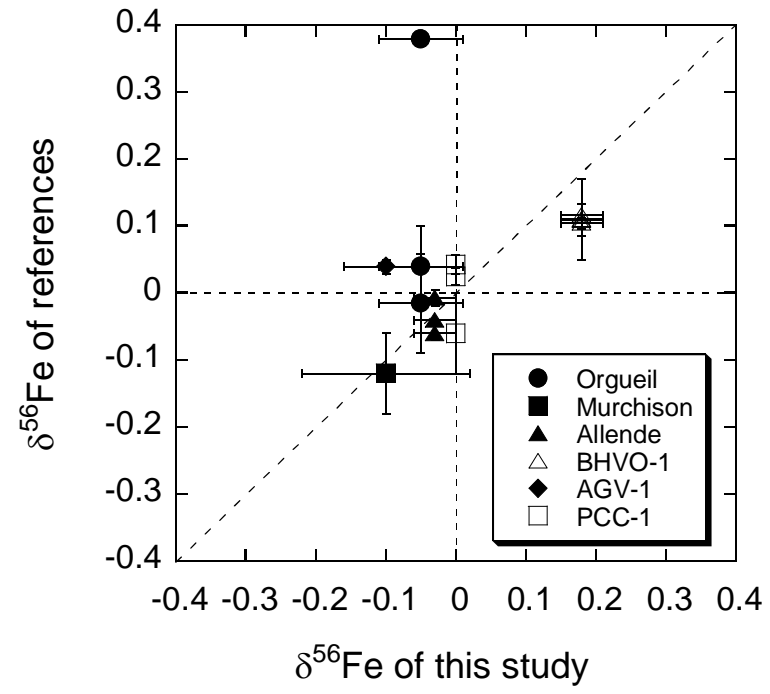

Figure 3. Iron isotope ratios $\left(\delta^{56} \mathrm{Fe}\right)$ of this study vs. those of references. The error bars show one standard deviation of repeatability (SD, \%). The vertical and horizontal dotted lines show $\delta^{56} \mathrm{Fe}=0$ of this study and references, respectively. The dotted slope line indicates slope $=1$, which means that there is no difference in $\delta^{56} \mathrm{Fe}$ between this study and references.

0.01\% using double-spike-MC-ICP-MS. The largest difference of this study from their study is 1) enrichment of the double spike and 2) larger usage of the sample. The ${ }^{56} \mathrm{Fe} /{ }^{54} \mathrm{Fe},{ }^{57} \mathrm{Fe} /{ }^{54} \mathrm{Fe}$ and ${ }^{58} \mathrm{Fe} /{ }^{54} \mathrm{Fe}$ ratios of the spike in this study are 24.5521, 53.0182 and 48.0436, while those of their spike are 2031, 67300 and 6812, respectively. This means that the denominator isotope, ${ }^{54} \mathrm{Fe}$ of this study is far more abundant than that or Millet et al. [11], resulting in lower precision. In addition, Millet et al. [11] used a $100 \mu \mathrm{L} \cdot \mathrm{min}^{-1}$ nebulizer and $2 \mu \mathrm{g} \cdot \mathrm{mL}^{-1}$ solution, totally 4 times larger amounts of Fe are used than that in this study.

\subsection{Application to Measurements of $\delta^{56} \mathrm{Fe}$ in Carbonaceous Chondrites}

The $\delta^{56} \mathrm{Fe}$ values of carbonaceous chondrites, Orgueil, Murchison and Allende were measured by the method developed in this study. The $\delta^{56} \mathrm{Fe}$ value of Orgueil of this study agrees well with those of Weyer et al. [26] and Kehm et al. [28], but that of Zhu et al. [27] seems a bit higher. The $\delta^{56} \mathrm{Fe}$ values of Allende of this study also agrees well with those of previous studies [22,27,28]. However, numbers of analyses of carbonaceous chondrites in literatures are limited, and carbonaceous chondrites could be heterogeneous, thus further studies are required.

Interference ratios of ${ }^{54} \mathrm{Cr} /{ }^{54} \mathrm{Fe}$ and ${ }^{58} \mathrm{Ni} /{ }^{58} \mathrm{Fe}$ in these carbonaceous chondrite analyses after the column chemistry were $<1.6 \times 10^{-3}$ and $<1.4 \times 10^{-4}$, respectively. Large $\mathrm{Cr}$ and $\mathrm{Ni}$ corrections were needed in the TEVA column chemistry developed in this study, however, the analytical results suggest that the single-pass TEVA column is sufficient even in analyses of $\mathrm{Cr}$ rich samples such as peridotites $\left(\sim 3000 \mu \mathrm{g} \cdot \mathrm{g}^{-1}\right)$ or chondrites $(\sim 4000$ $\left.\mu \mathrm{g} \cdot \mathrm{g}^{-1}\right)$.

\section{Conclusions}

Using an extraction resin, TEVA, new column chemistry for separating $\mathrm{Fe}$ has been developed for $\mathrm{Fe}$ isotope ratio determination by MC-ICP-MS. Iron was purified by 6 $\mathrm{mol} \cdot \mathrm{L}^{-1} \mathrm{HCl}+\mathrm{H}_{2} \mathrm{O}_{2}$, and major elements were separated. Fe was finally recovered with $2 \mathrm{~mol} \cdot \mathrm{L}^{-1} \mathrm{HNO}_{3}$. The recovery yields and total blanks were $93.5 \% \pm 6.5 \%$ (SD) and $6 \mathrm{ng}$, respectively.

For evaluation of the separation method, Fe isotope ratios were measured by a double spike method using MC-ICP-MS, respectively. Repeatability obtained from actual analyses of USGS standard reference materials of 
BHVO-1, AGV-1, PCC-1, and GSJ standard silicate materials of JB-1, JB-2, JB-3, JA-1, JA-2 and JA-3 were $0.05 \%$ (SD). Fe isotope ratios of carbonaceous chondrites of Orgueil, Murchison and Allende were also determined by the column chemistries developed in this study.

\section{Acknowledgements}

The author thanks to E. Nakamura for suggestions and supports at various aspects of this study. The author is also grateful to K. Tanaka for doing column chemistry; and T. Moriguti, C. Sakaguchi and all members of PML for maintaining the clean laboratory. The author is also grateful to $\mathrm{K}$. Okabe for donating ferruginous protein bodies.

\section{REFERENCES}

[1] E. P. Horwitz, M. L. Dietz, R. Chiarizia, H. Diamond, S. L. III Maxwell and M. R. Nelson, "Separation and Preconcentration of Actinides by Extraction Chromatography Using a Supported Liquid Anion-Exchanger-Application to the Characterization of High-Level Nuclear Waste Solutions," Analytica Chimica Acta, Vol. 310, No. 1, 1995, pp. 63-78. http://dx.doi.org/10.1016/0003-2670(95)00144-O

[2] X.-J. Yang and C. Pin, "Separation of Hafnium and Zirconium from Ti and Fe-Rich Geological Materials by Extraction Chromatography," Analytical Chemistry, Vol. 71, No. 9, 1999, pp. 1706-1711. http://dx.doi.org/10.1021/ac980833w

[3] Z. Grahek and M. R. Macefat, "Isolation of Iron and Strontium from Liquid Samples Anddetermination of Fe-55 and Sr-89, Sr-90 in Liquid Radioactive Waste," Analytica Chimica Acta, Vol. 511, No. 2, 2004, p. 339. http://dx.doi.org/10.1016/j.aca.2004.01.049

[4] A. Makishima and E. Nakamura, "Low-Blank Chemistry for $\mathrm{Zn}$ Stable Isotope Ratio Determination Using Extraction Chromatographic Resin and Double Spike-Multiple Collector-ICP-MS," Journal of Analytical Atomic Spectrometry, Vol. 28, 2013, pp. 127-133. http://dx.doi.org/10.1039/c2ja30271c

[5] A. Makishima, M. Nakanishi and E. Nakamura, "A Group Separation Method of Ruthenium, Palladium, Rhenium, Osmium, Iridium and Platinumusing Their Bromo Complexes and an Anion Exchange Resin," Analytical Chemistry, Vol. 73, No. 21, 2001, pp. 5240-5248. http://dx.doi.org/10.1021/ac010615u

[6] D. M. Borrok, R. B. Wanty, W. I. Ridley, R. Wolf, P. J. Lamothe and M. Adams, "Separation of Copper, Iron, and Zinc from Complex Aqueous Solutions for Isotopic Measurement," Chemical Geology, Vol. 242, No. 3-4, 2007, pp. 400-414. http://dx.doi.org/10.1016/j.chemgeo.2007.04.004

[7] N. Dauphas and O. Rouxel, "Mass Spectrometry and Natural Variations of Iron Isotopes," Mass Spectrometry Reviews, Vol. 25, No. 4, 2006, pp. 515-550. http://dx.doi.org/10.1002/mas.20078

[8] M. H. Dodson, "A Theoretical Study of the Use of Internal Standards for Precise Isotopic Analysis by the Surface Ionization Technique: Part I-General First-Order Algebraic Solutions," Journal of Scientific Instruments, Vol. 40, 1963, pp. 289-295.

http://dx.doi.org/10.1088/0950-7671/40/6/307

[9] C. M. Johnson and B. L. Beard, "Correction of Instrumentally Produced Mass Fractionation during Isotopic Analysis of Fe by Thermal Ionization Mass Spectrometry," International Journal of Mass Spectrometry, Vol. 193, No. 1, 1999, pp. 87-99. http://dx.doi.org/10.1016/S1387-3806(99)00158-X

[10] J. F. Rudge, B. C. Reynolds and B. Bourdon, "The Double Spike Toolbox," Chemical Geology, Vol. 265, No. 3-4, 2009, pp. 420-431. http://dx.doi.org/10.1016/j.chemgeo.2009.05.010

[11] M.-A. Millet, J. A. Baker and C. E. Payne, "Ultra-Precise Stable Fe Isotope Measurement by High Resolution Multiple-Collector Inductively Coupled Plasma Mass Spectrometry with a ${ }^{57} \mathrm{Fe}-{ }^{58} \mathrm{Fe}$ Double Spike," Chemical Geology, Vol. 304-305, 2012, pp. 18-25. http://dx.doi.org/10.1016/j.chemgeo.2012.01.021

[12] E. Nakamura, A. Makishima, T. Moriguti, K. Kobayashi, C. Sakaguchi, T. Yokoyama, R. Tanaka, T. Kuritani and H. Takei, "Comprehensive Geochemical Analyses of Small Amounts (100 mg) of Extraterrestrial Samples for the Analytical Competition Related to the Sample-Return Mission, MUSES-C," The Institute of Space and Astronautical Science Report, SP No. 16, 2003, pp. 49-101.

[13] A. Makishima and E. Nakamura, "Determination of Major, Minor and Trace Elements in Silicate Samples by ICP-QMS and ICP-SFMS Applying Isotope Dilution-Internal Standardization (ID-IS) and Multi-Stage Internal Standardization," Geostandards and Geoanalytical Research, Vol. 30, No. 3, 2006, pp. 245-271. http://dx.doi.org/10.1111/j.1751-908X.2006.tb01066.x

[14] T. Yokoyama, A. Makishima and E. Nakamura, "Evaluation of the Coprecipitation of Incompatible Trace Elements with Fluoride during Silicate Rock Dissolution by Acid Digestion," Chemical Geology, Vol. 157, No. 3, 1999, pp. 175-187. http://dx.doi.org/10.1016/S0009-2541(98)00206-X

[15] A. Makishima and E. Nakamura, "Precise Isotopic Determination of $\mathrm{Hf}$ and $\mathrm{Pb}$ at Sub-Nano Gram Levels by MC-ICPMS Employing a Newly Designed Sample Cone and a Pre-Amplifier with a $10^{12}$ Ohm Register," Journal of Analytical Atomic Spectrometry, Vol. 25, No. 11, 2010, pp. 1712-1716. http://dx.doi.org/10.1039/c0ja00015a

[16] A. Yamakawa, K. Yamashita, A. Makishima and E. Nakamura, "Chemical Separation and Mass Spectrometry of $\mathrm{Cr}, \mathrm{Fe}, \mathrm{Ni}, \mathrm{Zn}$ and $\mathrm{Cu}$ in Terrestrial and Extraterrestrial Materials Using Thermal Ionization Mass Spectrometry," Analytical Chemistry, Vol. 81, No. 23, 2009, pp. 97879794. http://dx.doi.org/10.1021/ac901762a

[17] P. D. P. Taylor, R. Maeck and P. De Bievre, "Determination of the Absolute Isotopic Composition and AtomicWeight of a Reference Sample of Natural Iron," International Journal of Mass Spectrometry and Ion Processes, Vol. 121, No. 1-2, 1992, pp. 111-125. 
http://dx.doi.org/10.1016/0168-1176(92)80075-C

[18] N. Dauphas, P. E. Janney, R. A. Mendybaev, M. Wadhwa, F. M. Richter, A. M. Davis, M. van Zuilen, R. Hines and C. N. Foley, "Chromatographic Separation and Multicollection-ICPMS Analysis of Iron. Investigating MassDependent and -Independent Isotope Effects," Analytical Chemistry, Vol. 76, No. 19, 2004, pp. 5855-5863. http://dx.doi.org/10.1021/ac0497095

[19] A. Makishima and E. Nakamura, "New Preconcentration Technique of $\mathrm{Zr}, \mathrm{Nb}$, Mo, Hf, Ta and W Employing Coprecipitation with Ti Compounds: Its Application to LuHf System and Sequential Pb-Sr-Nd-Sm Separation," Geochemical Journal, Vol. 42, No. 2, 2008, pp. 199-206. http://dx.doi.org/10.2343/geochemj.42.199

[20] S. G. Nielsen, M. Rehkämper, J. Baker and A. N. Halliday, "The Precise and Accurate Determination of Thallium Isotope Compositions and Concentrations for Water Samples by MC-ICPMS," Chemical Geology, Vol. 204, No. 1, 2004, pp. 109-124. http://dx.doi.org/10.1016/j.chemgeo.2003.11.006

[21] E. Nakamura, A. Makishima, K. Hagino and K. Okabe, "Accumulation of Radium in Ferruginous Protein Bodies Formed in Lung Tissue: Association of Resulting Radiation Hotspots with Malignant Mesothelioma and Other Malignancies," Proceedings of the Japan Academy, Series $B$, Vol. 85, 2009, pp. 229-239. http://dx.doi.org/10.2183/pjab.85.229

[22] P. R. Craddock and N. Dauphas, "Iron Isotopic Compositions of Geological Reference Materials and Chondrites," Geostandards and Geoanalytical Research, Vol. 35, No. 1, 2011, pp. 101-123.
http://dx.doi.org/10.1111/j.1751-908X.2010.00085.x

[23] O. J. Rouxel, A. Bekker and K. J. Edwards, "Iron Isotope Constraints on the Archean and Paleoproterozoic Ocean Redox State," Science, Vol. 307, No. 5712, 2005, pp. 10881091. http://dx.doi.org/10.1126/science. 1105692

[24] J. A. Schuessler, R. Schoenberg and O. Sigmarsson, "Iron and Lithium Isotope Systematics of the Hekla Volcano, Iceland-Evidence for Fe Isotope Fractionation during Magma Differentiation," Chemical Geology, Vol. 258, No. 1-2, 2009, pp. 78-91.

http://dx.doi.org/10.1016/j.chemgeo.2008.06.021

[25] B. L. Beard, C. M. Johnson, J. L. Skulan, K. H. Nealson, L. Cax and H. Sun, "Application of Fe Isotopes to Tracing the Geochemical and Biological Cycling of Fe," Chemical Geology, Vol. 195, No. 1, 2003, pp. 87-117. http://dx.doi.org/10.1016/S0009-2541(02)00390-X

[26] S. Weyer, A. D. Anbar, G. P. Brey, C. Muenker, K. Mezger and A. B. Woodland, "Iron Isotope Fractionation during Planetary Differentiation," Earth and Planetary Science Letters, Vol. 240, No. 2, 2005, pp. 251-264. http://dx.doi.org/10.1016/j.eps1.2005.09.023

[27] X. K. Zhu, Y. Guo, R. K. O’Nions, E. D. Young and R. D. Ash, "Isotopic Heterogeneity of Iron in the Early Solar Nebula," Nature, Vol. 412, No. 6844, 2001, pp. 311-313. http://dx.doi.org/10.1038/35085525

[28] K. Kehm, E. H. Hauri, C. M. O’D. Alexander and R. W. Carlson, "High Precision Iron Isotope Measurements of Meteoritic Material by Cold Plasma ICP-MS," Geochimica Cosmochimica Acta, Vol. 67, No. 15, 2003, pp. 2879-2891.

http://dx.doi.org/10.1016/S0016-7037(03)00080-2 